\title{
Flue gas desulfurization by mechanically and thermally activated sodium bicarbonate
}

\author{
Barbara Walawska1, Arkadiusz Szymanek ${ }^{2}$, Anna Pajdak², Marzena Nowak ${ }^{1}$ \\ ${ }^{1}$ Instytut Nawozów Sztucznych, Oddział Chemii Nieorganicznej „IChN” w Gliwicach, ul. Sowińskiego 11, 44-101 Gliwice, \\ Poland \\ ${ }^{2}$ Instytut Zaawansowanych Technologii Energetycznych, Wydziat Inżynierii Środowiska i Biotechnologii, Politechnika \\ Częstochowska, ul. J.H. Dąbrowskiego 73, 42-200 Częstochowa, Poland \\ "Corresponding author: e-mail: aszymanek@is.pcz.czest.pl
}

\begin{abstract}
This paper presents the results of study on structural parameters (particle size, surface area, pore volume) and the sorption ability of mechanically and thermally activated sodium bicarbonate. The sorption ability of the modified sorbent was evaluated by: partial and overall $\mathrm{SO}_{2}$ removal efficiency, conversion rate, normalized stoichiometric ratio (NSR). Sodium bicarbonate was mechanically activated by various grinding techniques, using three types of mills: fluid bed opposed jet mill, fine impact mill and electromagnetic mill, differing in grinding technology. Grounded sorbent was thermally activated, what caused a significant development of surface area. During the studies of $\mathrm{SO}_{2}$ sorption, a model gas with a temperature of $300^{\circ} \mathrm{C}$, of composition: sulfur dioxide at a concentration of $6292 \mathrm{mg} / \mathrm{m}_{\mathrm{n}}{ }^{3}$, oxygen, carbon dioxide and nitrogen as a carrier gas, was used. The best development of surface area and the highest $\mathrm{SO}_{2}$ removal efficiency was obtained for the sorbent treated by electromagnetic grinding, with simultaneous high conversion rate.
\end{abstract}

Keywords: flue gas desulfurization, sodium bicarbonate, surface area, conversion rate. \section{INTRODUCTION}

The process of coal combustion and accompanying emission of harmful substances is a current issue in terms of the power engineering. Emission standards for flue gases are gradually aggravated, thus in recent years a general downward trend in the course of the air quality index for Poland is observed ${ }^{1}$. Emission standards for pollutants from flue gases are determined, based on the nominal thermal power and on permission for construction and on emission source commissioning date. The permissible emissions are governed by national law compliant with EU law. For the coal-fired power station with a nominal thermal power of less than $5 \mathrm{MW}$, sulfur dioxide concentration in the flue gases shouldn't exceed $1500 \mathrm{mg} / \mathrm{m}^{3},(524 \mathrm{ppm})^{2}$. The reduction of $\mathrm{SO}_{2}$ emissions to required level can be achieved by: modernization or change of the combustion technology, desulfurization of the fuel before combustion or by using the technology of flue gas desulfurization.

One of the desulfurization technologies is flue gas dry treatment. This process depends on chemical bonding of $\mathrm{SO}_{2}$ in flue gas - solid sorbent system. The sorbent is mostly calcium-type, but sodium sorbent is also applicable. In the dry method the sorbent is injected directly into a flue gas, where it reacts with the acidic products of the combustion process. The dry method can be introduced to both new and an existing power plants. Due to the low implementation and running costs, even the small plants can easily implement this type of solution.

The increased interest in sodium sorbents - they can be either naturally occurring minerals: trona $\left(\mathrm{Na}_{3}\left(\mathrm{CO}_{3}\right)\right.$ $\left(\mathrm{HCO}_{3}\right) \cdot 2 \mathrm{H}_{2} \mathrm{O}$ ), nahcolite (mainly $\mathrm{NaHCO}_{3}$ ) or synthetic sodium bicarbonate - results from their good sorption of sulfur dioxide and of the other acidic pollutants (such as $\mathrm{NO}_{\mathrm{x}}, \mathrm{HCl}$ and $\mathrm{HF}$ ), present in the gaseous products of solid fuels combustion. The limestone, commonly used in the flue gas dry treatment, has a good sorption ability only at temperatures about $850^{\circ} \mathrm{C}$, while sodium bicarbonate works at much lower temperatures $\left(140-300^{\circ} \mathrm{C}\right)^{3}$.
In this temperature range the sorption ability of sodium bicarbonate is also much higher, compared with sodium carbonate. For the same temperature used and contact times of the sorbent with gases containing $\mathrm{SO}_{2}$, sodium bicarbonate has a few times higher conversion rate ${ }^{4}$. The reaction of sodium bicarbonate with $\mathrm{SO}_{2}$ can be described by the equation ${ }^{5}$ :

$2 \mathrm{NaHCO}_{3(\mathrm{~s})}+\mathrm{SO}_{2(\mathrm{~g})}+\mathrm{x} 1 / 2 \mathrm{O}_{2(\mathrm{~g})} \rightarrow(1-\mathrm{x}) \mathrm{Na}_{2} \mathrm{SO}_{3(\mathrm{~s})}+$ $\mathrm{x} \mathrm{Na} \mathrm{SO}_{4(\mathrm{~s})}+2 \mathrm{CO}_{2(\mathrm{~g})}+\mathrm{H}_{2} \mathrm{O}_{(\mathrm{g})}$

In the literature a several models of this process are described. This variety is caused by the thermal decomposition of sodium bicarbonate, which influence the $\mathrm{SO}_{2}$ removal efficiency. Keener and Khang ${ }^{6}$ proposed a multipath model of the $\mathrm{SO}_{2}$ reaction with sodium bicarbonate grains: direct or indirect, which is parallel to direct. The proposed model assumes that used sodium bicarbonate is a non-porous material with a low surface area. In the direct model, the reaction occurs on the surface of non-porous sodium bicarbonate according to the equation:

$2 \mathrm{NaHCO}_{3}+\mathrm{SO}_{2} \rightarrow \mathrm{Na}_{2} \mathrm{SO}_{3}+2 \mathrm{CO}_{2}+\mathrm{H}_{2} \mathrm{O}$

As the reaction progress, the sodium bicarbonate surface area contracts, leading to decrease of molar volume of reaction products and the formation of numerous pores at the surface of grains.

In the indirect model, during the decomposition of sodium bicarbonate, formed sodium carbonate develop an increased porosity of grains and extended "popcorn" type active surface area (3). In contact with the sulfur dioxide present in flue gas sodium sulfite forms (4).

$2 \mathrm{NaHCO}_{3} \rightarrow \mathrm{Na}_{2} \mathrm{CO}_{3}+\mathrm{H}_{2} \mathrm{O}(\mathrm{g})+\mathrm{CO}_{2}(\mathrm{~g})$

$\mathrm{Na}_{2} \mathrm{CO}_{3}+\mathrm{SO}_{2} \rightarrow \mathrm{Na}_{2} \mathrm{SO}_{3}+\mathrm{CO}_{2}$

The overall conversion of $\mathrm{Na}_{2} \mathrm{SO}_{3}$ to $\mathrm{NaHCO}_{3}$ is the sum of the partial conversions obtained for the established reaction path. The product, sodium sulfite, which, in contact with oxygen from flue gas, forms sodium sulfate according to the reaction:

$\mathrm{Na}_{2} \mathrm{SO}_{3}+1 / 2 \mathrm{O}_{2} \rightarrow \mathrm{Na}_{2} \mathrm{SO}_{4}$ 
Basing on the results of $\mathrm{SO}_{2}$ sorption at a temperature of about $250^{\circ} \mathrm{C}$, Garding and Svedberg ${ }^{7}$ proposed skipping the stage of the thermal decomposition of bicarbonate in a kinetic model of the process due to the very high speed of the reaction. They limited factors affecting the process speed to resistance of diffusion through the gas film (external film diffusion), diffusion inside the grain (diffusion through reacted material) and the chemical reaction. Another model of the process was presented by Kimura and $\mathrm{Smith}^{8}$, who have conducted the studies in the temperature range of $80-180^{\circ} \mathrm{C}$, using a sodium bicarbonate previously decomposed at $180^{\circ} \mathrm{C}$. The reaction mechanism proposed by these authors vary with the temperature of the process - sodium carbonate can react with $\mathrm{SO}_{2}$, either in direct or indirect way. In the temperature range of $80-140^{\circ} \mathrm{C}$, the sodium sulfite is formed indirectly by formation of intermediate products after $\mathrm{SO}_{2}$ adsorption and $\mathrm{CO}_{2}$ desorption from the active surface of the grains. The direct reaction of sodium carbonate with $\mathrm{SO}_{2}$ occurs at the temperatures above $140^{\circ} \mathrm{C}$.

The effectiveness of sodium sorbents used in dry desulfurization processes is commonly assessed by three criteria":

- sulfur dioxide removal efficiency

amount of $\mathrm{SO}_{2}$ removed from flue gases

amount of $\mathrm{SO}_{2}$ introduced with flue gases $\cdot 100 \%$

- degree of utilization of sodium contained in a dry sorbent, i.e. the conversion rate:

amount of $\mathrm{Na}_{2}$ moles reacting with $\mathrm{SO}_{2}$

amount of $\mathrm{Na}_{2}$ moles introduced with sorbent

$100 \%$

- normalized stoichiometric ratio (NSR), associated with the first two criteria:

$\mathrm{SO}_{2}$ removal efficiency $\%$

convesion rate $\%$

The above criteria are affected by several parameters associated with both the purified gas and a sorbent used: process temperature, contact time of the sorbent with the purified gas, $\mathrm{SO}_{2}$ concentration in purified gas, sodium sorbent particle diameter and its type, which were the subjects of several studies, ${ }^{3 \mathbf{1 0}, 11}$. The process temperature and contact time are closely related to the injection of the sorbent into purified gas, thus studies focus in the temperature range of $140-300^{\circ} \mathrm{C}$. At higher temperatures, the pores plugging occurs, reducing the conversion rate of sorbents. To increase the sorption ability of sodium sorbent, the mechanical activation (mainly grinding), before introduction of the sorbent to the gas stream, is used ${ }^{12}$.

The results of laboratory tests of the impact of mechanical and thermal activation of synthetic sodium bicarbonate on the textual parameters and on $\mathrm{SO}_{2}$ removal efficiency from the model gases and the conversion rate are shown below.

\section{EXPERIMENTAL PART}

For the studies, sodium bicarbonate in the form of baking soda (of standard class) and sodium carbonate were used. Both are produced by Soda Polska Ciech S.A., with characteristics shown in Tables 1 and 2.

Sodium bicarbonate was activated mechanically by grinding in three types of mills: fluid bed opposed jet
Table 1. Multifunctional methacrylates and photoinitiator used in this work

\begin{tabular}{|l|c|}
\hline Parameter & Value \\
\hline Content $[\%]:$ & $98.7-99.2$ \\
$\mathrm{NaHCO}_{3}$ & 0.04 \\
Moisture $\left(50^{\circ} \mathrm{C}\right)$ & 126.0 \\
\hline Average grain, $\mathrm{d}_{4,3}[\mu \mathrm{m}]$ & 0.07 \\
Surface area $\left[\mathrm{m}^{2} / \mathrm{g}\right]$ & \\
\hline
\end{tabular}

Table 2. Monomers parameters and shrinkage of tested dental compositions

\begin{tabular}{|l|c|}
\hline Parameter & Value \\
\hline Content [\%]: & $>99.5$ \\
$\mathrm{Na}_{2} \mathrm{CO}_{3}$ & $<0.5$ \\
Ignition losses [\%] & 107.8 \\
\hline Average grain, $\mathrm{d}_{4,3}[\mu \mathrm{m}]$ & 0.08 \\
\hline Surface area $\left[\mathrm{m}^{2} / \mathrm{g}\right]$ & \\
\hline
\end{tabular}

mill, fine impact mill and electromagnetic mill, differing in grinding technique. The $100 \mathrm{AFG}$ fluid bed mill from Hosokawa-Alpine was used for opposed jet milling, where the energy required to mill the material is passed through the intersecting streams of compressed air. The milling effect is obtained by collisions of particles itself and with the mill chamber walls. An equipped separator provided a product with a narrow particle size distribution. The 160 UPZ mill from Hosokawa-Alpine was used for impact milling. Milling of the material was due to impact of the steel tines spaced on the shield and on the spinning rotor. The milling was conducted at rotor speed of $11400 \mathrm{rpm}$ and with an efficiency of $60 \mathrm{~kg} / \mathrm{h}$. In the electromagnetic mill, the grinding was due to collisions of grains with ferromagnetic grinding media, in a rotating magnetic field. In the grinding chamber a very rapid and turbulent grinding process occurs. As results, the obtained material has a very good reactive properties ${ }^{13}$.

Particle size distribution of products after mechanical activation was measured on a Beckman Coulter laser analyzer LS 13320, using a wet measuring module. Applied method was consistent with ISO requirements on particle size analysis by laser scattering method ${ }^{14}$. As a result of mechanical activation, a grounded sorbent with different average grain of respectively: $\mathrm{d}_{4,3}=6.7 \mu \mathrm{m}$; $13.2 \mu \mathrm{m} ; 32.8 \mu \mathrm{m}$ was obtained.

Application of different milling techniques resulted in changes in the structure and texture of the grains surface, which has become apparent after the thermal activation. The thermal activation was conducted at $300^{\circ} \mathrm{C}$ for 30 minutes, to complete decomposition of sodium bicarbonate to sodium carbonate. The evaluation of the structure and texture of grains surface was made before and after thermal activation; the surface area and the total pore volume of sorbent were determined. For the selected sorbents, the surface area was analyzed by electron microscopy.

To measure the active surface area of sorbents, the method of Brunauer, Emmett, Teller (BET) was used. Tests were carried out on the Gemini VII 2390 A type surface area analyzer, which measures the volume of gas adsorbed at the temperature of $-196^{\circ} \mathrm{C}$ in the relative pressure range of $0.03-0.5$. The surface area, which comprises surface of solid, surface of open pores $\left(\mathrm{m}^{2} / \mathrm{g}\right)$, and total pore volume $(\mathrm{mL} / \mathrm{g})$, are factors determining the adsorption properties and allow to classify the material in accordance with the IUPAC (International 
Union of Pure and Applied Chemistry) recommendations ${ }^{15}$. The total pore volume was determined by mercury porosimeter Auto Pore IV 9500 (Automated Porosimeters Mercury). The measurement technique is based on mercury intrusion in porous structures under strictly controlled pressure or time intervals, allowing to measure the pore size distribution in the range of 0.003 microns -1000 microns.

Sorbent's structure was evaluated, using a Scanning Microscope Philips XL 30 ESEM with EDS Edax (SEM), allowing surface texture mapping. Using SE detector (secondary electrons), images of samples (using gold sputtering) were recorded with zoom of 1000 to 20000x.

After assessing the impact of mechanical activation on the particle size distribution and on the structure of surface area, investigated sorbents were studied in aspect of $\mathrm{SO}_{2}$ removal. The test was carried out on laboratory test bed as shown in Figure 1.

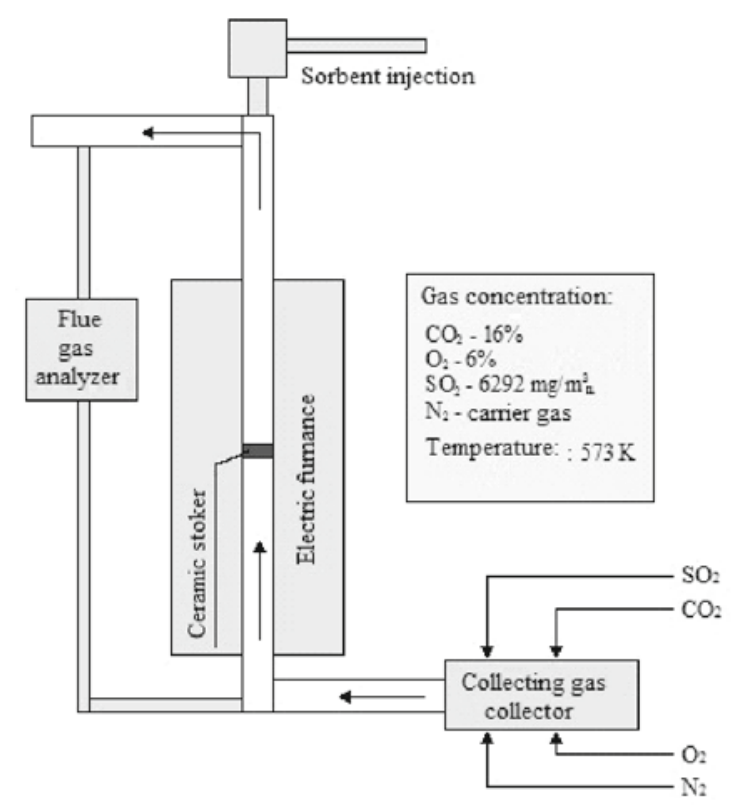

Figure 1. The laboratory test bed to determine the sorption ability of the model gases

The main element of the test bed was electric furnace with a quartz column. The sorbent and a model gas containing sulfur dioxide at a concentration of $6292 \mathrm{mg} /$ $\mathrm{m}_{\mathrm{n}}{ }^{3}$ (2200 ppm), oxygen (6\%), carbon dioxide (16\%), and nitrogen as a carrier gas were introduced to the column. Established $\mathrm{SO}_{2}$ concentration in the model gas corresponds with the level of that contaminant in the flue gas from the coal combustion without the desulfurization $^{16}$. The temperature in the reaction chamber was maintained at the level of $300^{\circ} \mathrm{C}$ during whole experiment. The gas flow was controlled by dual regulation system: the controller coupled with flow meter and volumetric flow controller. The $\mathrm{SO}_{2}$ concentration was measured with flue gas analyzer GASMET DX-4000, in which the spectrum of gas is analyzed by FT-IR (Fourier Transform Infrared Spectroscopy) method. After the introduction of $6 \mathrm{~g}$ of the sorbent into the reaction zone, the analyzer registered $\mathrm{SO}_{2}$ concentration in flue gas in every 5 seconds and averaged to the value in every minute. The sorbent remained in stream of model gas during all time of the experiment. The heat lead to thermal activation of the sorbent and, as a result, to reduction of $\mathrm{SO}_{2}$ concentration in the flue gas. The measurement was stopped, when $\mathrm{SO}_{2}$ concentration in the flue gas returned to the initial value.

\section{DISCUSSION}

The evaluation of $\mathrm{SO}_{2}$ removal efficiency in the model gas was carried out by analysis the texture and the surface area of mechanically and thermally activated sorbents. The data were collected on physical properties of sorbents: grain size, surface area and texture, pore volumes and on their sorption properties: partial and total $\mathrm{SO}_{2}$ removal efficiency, conversion rate and normalized stoichiometric ratio NSR.

For the studies, the mechanically activated sorbents, which undergo three different techniques of grinding, were used. As a result of activation, the sorbents that vary on particle size distribution were achieved, as illustrated in Figure 2. The ungrounded sorbents: sodium carbonate and sodium bicarbonate have similar particle size distribution, what is confirmed by average grain size diameter of these sorbents: 127 and $107 \mu \mathrm{m}$ respectively and by their surface area: 0.07 and $0.08 \mathrm{~m}^{2} / \mathrm{g}$. For residual sorbent, mechanical activation shifts the unimodal particle size distribution toward the smaller particles, except of the sorbent grinded in a rotating magnetic field. For that sorbent bimodal particle size distribution suggests presence of two fractions of different particle size distribution and of a similar volume fraction. The identification of the samples are shown in the Table 3.

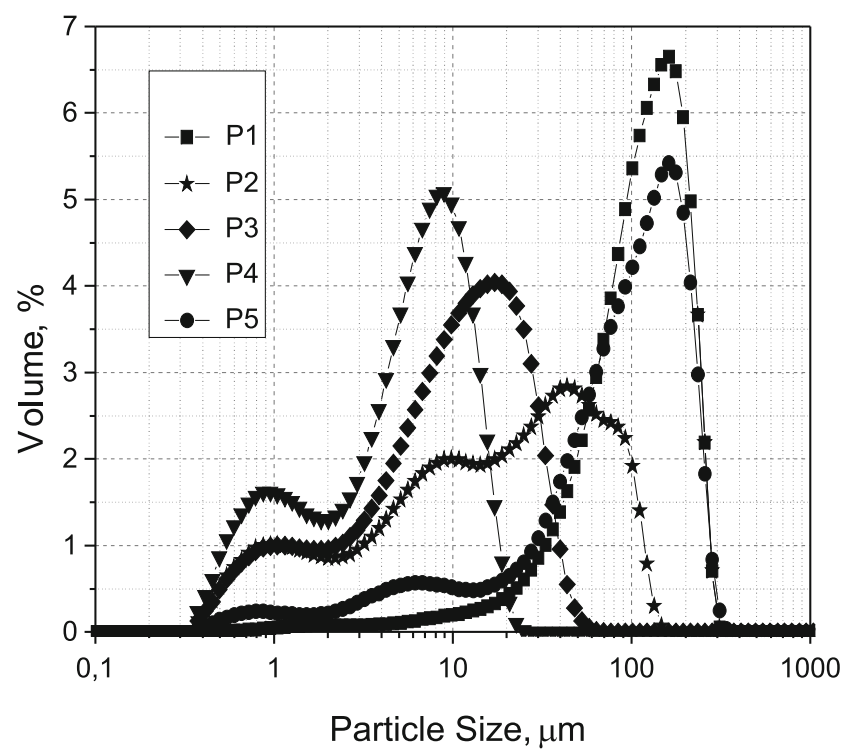

Figure 2. The particle size distribution of sodium carbonate and sodium bicarbonate

Performed grain size analysis and BET surface area measurements showed the relationship between the grain size and surface area of the material. The average particle diameters and the structural properties of sorbents are presented in Table 3.

Not activated thermally sodium bicarbonate, classified according to the IUPAC recommendations as a macroporous material ${ }^{15}$, has a poorly developed surface area. The milling of the material increased its surface area, in a degree depending on the type of milling. The most intensive development of the surface area was obtained 
Table 3. Monomers parameters and shrinkage of tested dental compositions

\begin{tabular}{|c|c|c|c|c|c|c|}
\hline \multirow[b]{2}{*}{$\begin{array}{l}\text { Sample } \\
\text { number }\end{array}$} & \multirow[b]{2}{*}{ Material } & \multirow[b]{2}{*}{$\begin{array}{c}\text { Average grain } \\
\mathrm{d}_{4,3}[\mu \mathrm{m}]\end{array}$} & \multirow[b]{2}{*}{$\begin{array}{c}\text { Type of mechanical } \\
\text { activation }\end{array}$} & \multicolumn{2}{|c|}{$\begin{array}{c}\text { Surface area } \\
{\left[\mathrm{m}^{2} / \mathrm{g}\right]}\end{array}$} & \multirow{2}{*}{$\begin{array}{c}\text { Total pore } \\
\text { volume }[\mathrm{mL} / \mathrm{g}] \\
\text { Thermal } \\
\text { activation in } \\
300^{\circ} \mathrm{C}\end{array}$} \\
\hline & & & & $\begin{array}{l}\text { Lack of thermal } \\
\text { activation }\end{array}$ & $\begin{array}{l}\text { Thermal } \\
\text { activation in } \\
300^{\circ} \mathrm{C}\end{array}$ & \\
\hline P1 & Baking soda & 127.0 & None & 0.07 & 2.09 & $300^{\circ} \mathrm{C}$ \\
\hline P2 & Baking soda & 32.8 & Electromagnetic mill & 0.65 & 8.64 & 0.86 \\
\hline P3 & Baking soda & 13.2 & Fine impact mill & 0.73 & 7.70 & 0.76 \\
\hline $\mathrm{P} 4$ & Baking soda & 6.7 & Fluid bed opposed jet mill & 1.30 & 4.90 & 0.76 \\
\hline P5 & Anhydrous soda & 107.8 & None & 0.08 & n.o. & 0.84 \\
\hline
\end{tabular}

for the smallest particles, i.e. after the activation in the fluid bed opposed jet mill $(6.7 \mu \mathrm{m})$.

In the milled and thermally activated sorbents further development of the active surface area was observed. Best values were obtained for the electromagnetically milled material $(32.8 \mu \mathrm{m})$, due to the unique method of milling, leading to increase of material's reactive properties.

SEM microphotographs confirm the previous grains structure analysis. Sodium bicarbonate not activated mechanically (Fig. 3. P1a) has a compact crystalline surface. The milling resulted in a cracking of the material and development of cracks and fissures on the grains surface (Fig. 3. P2a, P3a). Materials after thermal activation has diversified structure of the surface. In ungrounded sodium bicarbonate, larger - volume pores formed, but in the smaller amount (Fig. 3. P1b). On the grains of grounded sorbents, a small, numerous macro-pores developed (Fig. 3.P2b, P3b). These macro-pores form a shallow porous structure, covering the entire surface of the sorbents.
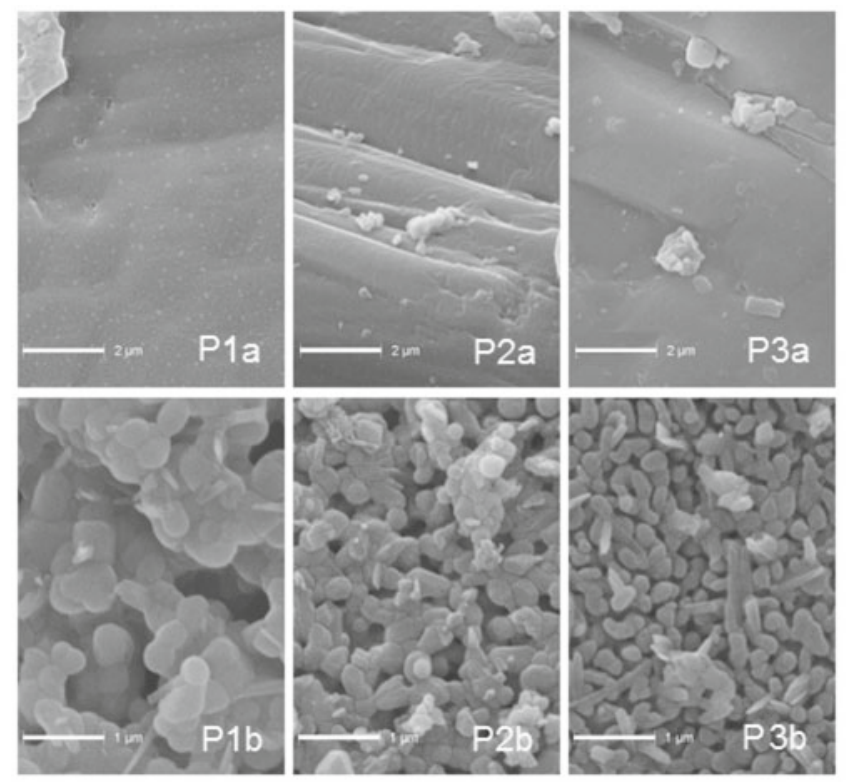

Figure 3. Microphotographs of the surface area of samples P1, P2 and P3 with a zoom: (a) x10000, (b) x20000

In order to determine the sorption ability, analyzed sorbents were introduced into the model gas stream containing sulfur dioxide. After several or tens minutes, $\mathrm{SO}_{2}$ concentration returned to baseline, as illustrated in Figure 4. Both level of pollution reduction and duration of sorbent action depends on the type of introduced sorbent, which clearly affected the $\mathrm{SO}_{2}$ concentration. To evaluate the sorbents, the partial $\mathrm{SO}_{2}$ removal efficiency in the time interval (Fig. 5) was determined:
$\varphi(t)=\frac{C_{0}-C_{t}}{C_{0}} \cdot 100 \%$

where:

$C_{0}-$ inlet $\mathrm{SO}_{2}$ concentration, ppm $\mathrm{SO}_{2}$,

$C_{\mathrm{t}}$ - outlet $\mathrm{SO}_{2}$ concentration after time t, $\mathrm{ppm} \mathrm{SO}_{2}$.

The dynamics and the efficiency of the desulfurization of tested sorbents varied. The sorbent of the finest grains (6.7 microns), obtained after mechanical activation on the fluid bed opposed jet mill, reacted the most quickly. Small grains with a higher initial surface reacted more intensely, and desulfurization process was much more dynamic, with highest decrease in $\mathrm{SO}_{2}$ concentration $\left(480 \mathrm{mg} / \mathrm{m}_{\mathrm{n}}^{3}\right)$ in all tested sorbents. For that sorbent the initial step of low reactivity, occurring in all the other sorbents, does not appear. This shift appears also in case of the sodium carbonate and may be due to heating of larger grains.

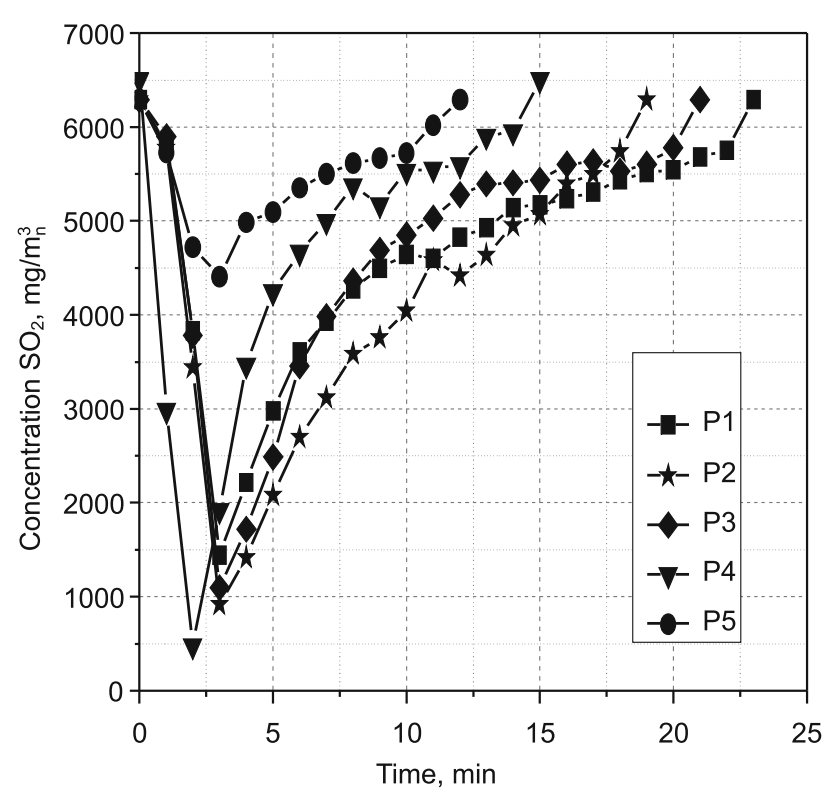

Figure 4. Changes of $\mathrm{SO}_{2}$ concentration in the flue gas during the studies of sorption ability of sodium sorbents

Among the tested sorbents, the least reactive was sodium carbonate, due to the lack of developed active surface area. The sodium carbonate used during the studies have particle size distribution and surface area similar to that of ungrounded sodium bicarbonate, which has through, significantly higher reactivity. The maximum $\mathrm{SO}_{2}$ removal efficiency obtained for sodium carbonate was only $30 \%$, while for ungrounded sodium bicarbonate it was $77 \%$. The mechanical activation on the fine impact mill and on the electromagnetic mill increased the maximum $\mathrm{SO}_{2}$ removal efficiency to the level of $85-83 \%$, but not as much as for the activation on the fluid bed opposed jet mill. 


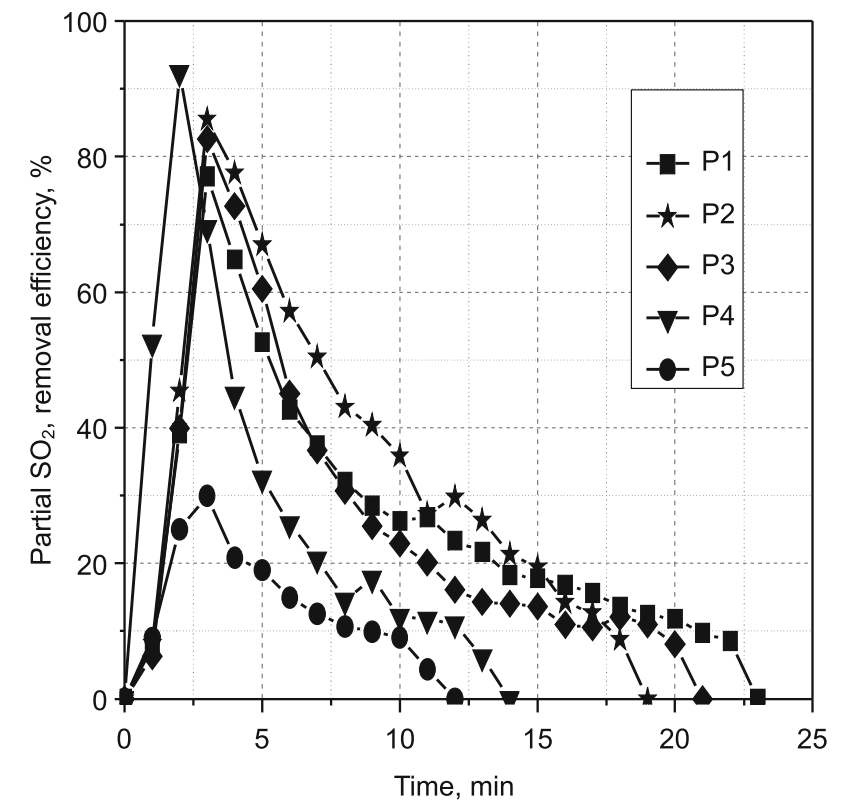

Figure 5. The partial $\mathrm{SO}_{2}$ removal efficiency in the flue gas during the studies of sorption ability of sodium sorbents

Measurements of $\mathrm{SO}_{2}$ concentration were used to determine the change of the conversion rate of used sorbents X (Fig. 6) and $\mathrm{SO}_{2}$ removal efficiency from the model gas $\varphi$ (Fig. 7) during the experiment. The conversion rate was determined as the ratio of moles of sodium $\left(\right.$ as $\left.\mathrm{Na}_{2}\right)$ participating in the reaction with $\mathrm{SO}_{2}$, calculated per $\mathrm{Na}_{2} \mathrm{SO}_{4}$ (which were calculated from changes of the sulfur dioxide concentration through the lack of the analysis of sorbents chemical compositions) and the amount of sorbent introduced into the reaction column, in accordance with the equation:

$X=2 \cdot \frac{V_{g} \cdot t \cdot M}{m} \cdot \int_{0}^{t}\left(C_{0}-C_{t}\right) d t \cdot 100 \%$

where:

$X$ - conversion rate: the molar ratio of the quantity of sorbent, which was converted to its initial quantity, $\%$ mole $\mathrm{Na}_{2} \mathrm{SO}_{4} / 2$ moles $\mathrm{NaHCO}_{3}$,

$V_{g}$ - the quantity of gas, $\mathrm{m}^{3} / \mathrm{min}$,

$m$ - the mass of sorbent, $\mathrm{g}$,

$t$ - the reaction time, min,

$M$ - the molar mass of the sorbent, $\mathrm{g} /$ mole.

The $\mathrm{SO}_{2}$ removal efficiency from the model gas, defined as the ratio of moles of $\mathrm{SO}_{2}$ removed from the gas to the number of moles of $\mathrm{SO}_{2}$ introduced, was calculated from the equation:

$\varphi=\frac{\int_{0}^{t}\left(C_{0}-C_{t}\right) d t}{C_{0}} \cdot 100 \%$

The calculated values of the conversion rate, similarly to distribution of $\mathrm{SO}_{2}$ concentrations, indicated that the least reactive from the tested sorbents was sodium carbonate. After the process, the conversion rate of carbonate was only $6 \%$. It was also associated with the shortest reaction time, proving blocking of grains surface by product of desulfurization. Replacement of sodium carbonate by sodium bicarbonate resulted a significant reduction of $\mathrm{SO}_{2}$ concentration in the flue gases and the change in the conversion rate, which increased with the decrease of material fragmentation.

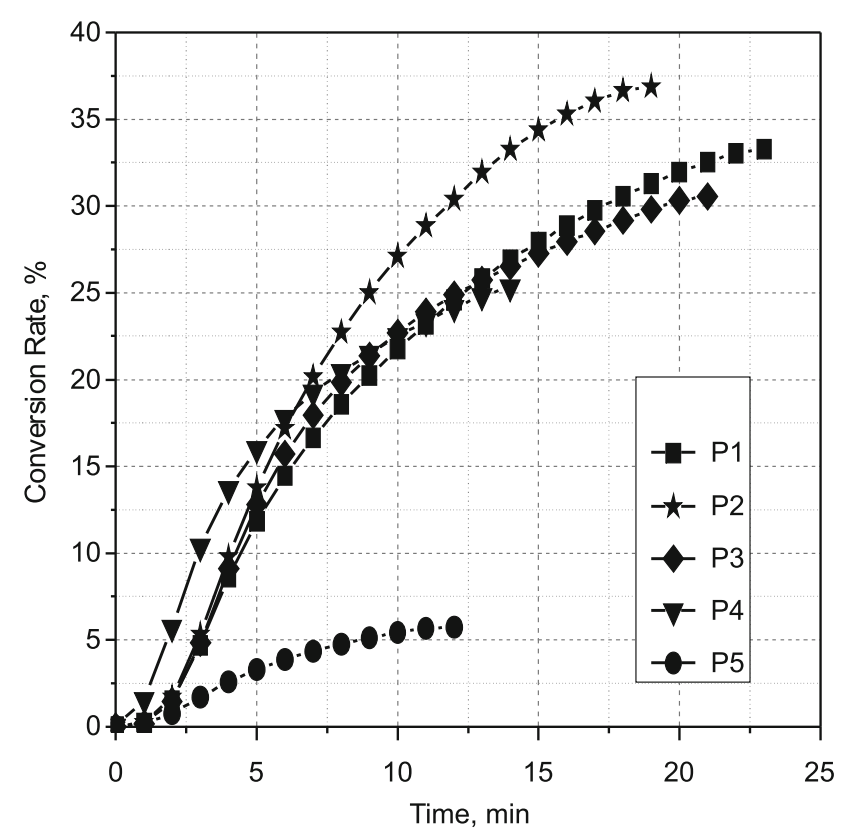

Figure 6. The molar conversion rates of studied sorbents

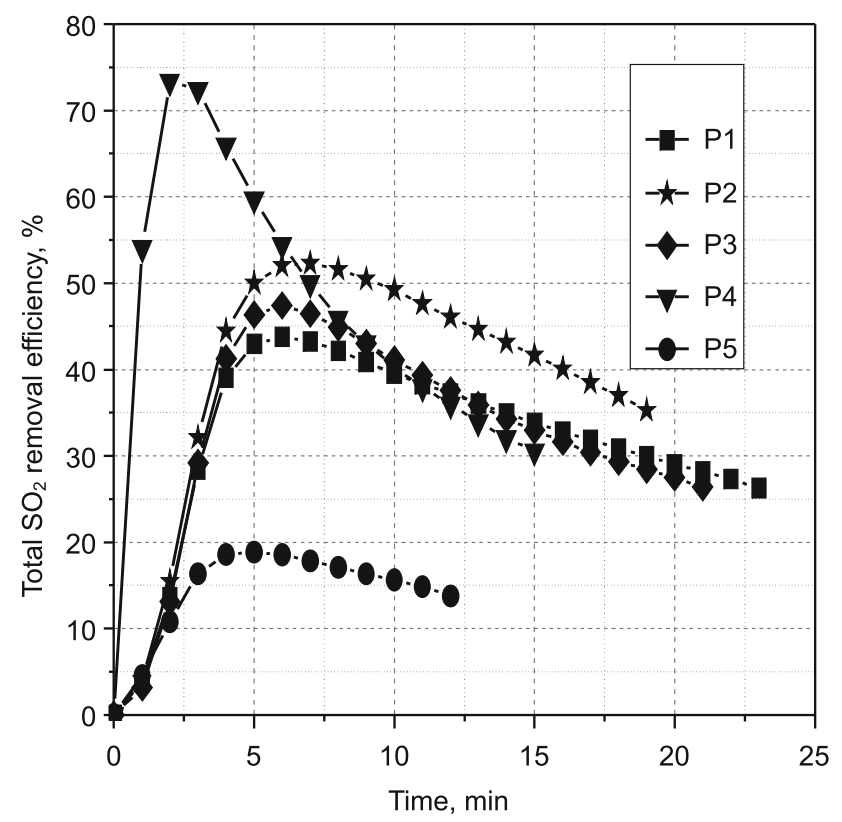

Figure 7. Total $\mathrm{SO}_{2}$ removal efficiency in the model gas

The results of sorbent subjected to electromagnetic grinding are especially interesting. Despite of the relatively large average grain $(32.8 \mu \mathrm{m})$ the highest conversion rate $-36.9 \%$ was obtained. This is a result of grinding in a constant magnetic field and obtaining the highest surface area $\left(8.6 \mathrm{~m}^{2} / \mathrm{g}\right)$. For ungrounded sorbent $(127 \mu \mathrm{m})$ and after the activation on the fine impact mill $(13.2 \mu \mathrm{m})$, the progresses of curves, showing the progressive conversion rate of sodium bicarbonate, were similar, but the end result depended essentially on the time period of the process - the longer the time, the higher conversion rate.

The high reactivity of the sorbent with smallest particle size $(6.7 \mu \mathrm{m})$ is also visible in the shape of conversion curve and in $\mathrm{SO}_{2}$ removal efficiency. For the short reaction times (up to $3 \mathrm{~min}$ ), the reaction rate is high, the conversion rate is several times higher than obtained for the other sorbents in the same time and also $\mathrm{SO}_{2}$ removal efficiency is very high up to $75 \%$. However, the low total conversion rate is surprising and can be 
Table 4. Monomers parameters and shrinkage of tested dental compositions

\begin{tabular}{|c|c|c|c|c|c|}
\hline \multirow[b]{2}{*}{ Parameters } & \multirow{2}{*}{$\begin{array}{c}\text { Sodium } \\
\text { carbonate, without } \\
\text { mechanical } \\
\text { activation }\end{array}$} & \multicolumn{4}{|c|}{ Sodium bicarbonate } \\
\hline & & $\begin{array}{c}\text { Without } \\
\text { mechanical } \\
\text { activation }\end{array}$ & $\begin{array}{l}\text { Electromagnetic } \\
\text { mill }\end{array}$ & Fine impact mill & $\begin{array}{l}\text { Fluid bed opposed } \\
\text { jet mill }\end{array}$ \\
\hline $\begin{array}{l}\text { Average grain } \\
\mathrm{d}_{4,3}[\mathrm{um}]\end{array}$ & 107.8 & 127.0 & 32.8 & 13.2 & 6.7 \\
\hline Surface area, $300^{\circ} \mathrm{C}\left[\mathrm{m}^{2} / \mathrm{g}\right]$ & 0.08 & 2.09 & 8.64 & 7.70 & 4.90 \\
\hline $\begin{array}{l}\text { Total pore volume, } 300^{\circ} \mathrm{C} \\
{[\mathrm{mL} / \mathrm{g}]}\end{array}$ & None & 0.86 & 0.76 & 0.76 & 0.84 \\
\hline Reaction time, $\min$ & 12 & 23 & 19 & 20 & 15 \\
\hline $\begin{array}{l}\text { Max. } \mathrm{SO}_{2} \text { removal efficiency } \\
{[\%]}\end{array}$ & 300 & 77.1 & 85.5 & 82.6 & 95.8 \\
\hline $\mathrm{SO}_{2}$ removal efficiency [\%] & 13.8 & 26.3 & 35.3 & 26.4 & 30.5 \\
\hline Conversion rate $[\%]$ & 5.7 & 33.3 & 36.9 & 30.6 & 26.1 \\
\hline $\begin{array}{l}\mathrm{NSR}, \\
\mathrm{Na}_{2} \text { mole/ } / \mathrm{SO}_{4} \text { mole }\end{array}$ & 2.40 & 0.79 & 0.96 & 0.86 & 1.20 \\
\hline
\end{tabular}

related to the problem of maintaining the fine particles in the fluidized bed. A part of the sorbent was probably entrained by the gas stream, thus relatively short time of the sorption process had a significant influence on the final result defining the conversion rate. For other sorbents after mechanical activation and for ungrounded sodium bicarbonate, the highest $\mathrm{SO}_{2}$ removal efficiency was achieved only after 6-7 minutes. However, for the sorbent without mechanical activation $\mathrm{SO}_{2}$ removal efficiency was lower $-44 \%$ vs. $47-52 \%$ after activation. The lowest - about $19 \%$ was obtained for sodium carbonate, which did not develop active surface area.

Table 4 shows the calculated values of the criteria discussed above, set for the total times of the sorption process with parameters, that may impact these values for all tested sorbents.

The obtained results show that sodium bicarbonate is more reactive sorbent, compared with sodium carbonate. These differences are particularly apparent during comparison of sodium carbonate with mechanically unmodified sodium bicarbonate. The impact of the grain size diameter on the $\mathrm{SO}_{2}$ removal efficiency from model gas can be omitted, because both sorbents have a similar particle size distribution. The visible increase in surface area, caused by the thermal decomposition of sodium bicarbonate treated by thermal activation, contributed to increase its sorption ability. This effect has not been observed for sodium carbonate.

The highest $\mathrm{SO}_{2}$ removal efficiency and a simultaneous high conversion rate were obtained for the sorbent grinded on electromagnetic mill. That effect was achieved at a molar ratio $\mathrm{Na}_{2} / \mathrm{SO}_{4}$ a bit lower, than stoichiometric ratio. The deficiency of sorbent was also reported for sodium bicarbonate without mechanical activation and after grinding on fine impact mill, what had an impact on the conversion rate. A small stoichiometric excess $\mathrm{Na}_{2} /$ $\mathrm{SO}_{4}$, that occurred for the finest sorbent, is the result of a lower conversion rate, compared with the other sorbents. NSR was the highest for sodium carbonate -2.4 moles $\mathrm{Na}_{2}$ per mole of $\mathrm{SO}_{4}$, due to a very low conversion rate.

\section{CONCLUSION}

The high reactivity of sodium bicarbonate in the process of $\mathrm{SO}_{2}$ removal is the result of both its chemical reactivity and applied activation (mechanical and thermal). Grinding method used during mechanical activation affects surface properties (particle size distribution and forming of cracks and fractures), which determines the effects of thermal activation. Depending on the degree of fineness, the materials of even several times larger surface area are obtained, e.g. by grinding on fluid bed opposed jet mill, the increase from $0.07 \mathrm{~m}^{2} / \mathrm{g}$ to $1.3 \mathrm{~m}^{2} / \mathrm{g}$ was achieved. The thermal activation performed at a temperature above the decomposition temperature of sodium bicarbonate $\left(300^{\circ} \mathrm{C}\right)$ results in a further development of the surface area. On the grains of sorbent a number of macro-pores are formed, creating a "popcorn" type structure, where the pore size depends on particle diameter. In the ungrounded sodium bicarbonate, a smaller quantities of large volume pores are formed, while grounded products have more smaller pores. The resulting structure has a significant influence on increase of the surface area. For sodium bicarbonate not treated by mechanical activation, the thermal activation increased its surface area from 0.07 to $2.09 \mathrm{~m}^{2} / \mathrm{g}$, for grounded materials that effect was even more visible - from 0.65 to $8.64 \mathrm{~m}^{2} / \mathrm{g}$.

The effects of mechanical and thermal activation have a significant impact on the results of $\mathrm{SO}_{2}$ sorption, what is particularly evident when compared with untreated sodium carbonate. All assumed indicators of the evaluation of sorption ability of sodium bicarbonate show its very good sorption ability. The maximum partial $\mathrm{SO}_{2}$ removal efficiency obtained during the study is $95.8 \%$ for the sodium bicarbonate of the finest grain $(6.7 \mu \mathrm{m})$. High $\mathrm{SO}_{2}$ removal efficiency (above $80 \%$ ) was obtained also for other grounded materials; for ungrounded sorbent it was below $80 \%$. Also, the overall $\mathrm{SO}_{2}$ removal efficiency and the conversion rate obtained during the studies were significantly higher in case of sodium bicarbonate, than for sodium carbonate, which, in fact, is directly involved in a chemical process of $\mathrm{SO}_{2}$ removal. Such positive results of sorption for sodium bicarbonate were obtained with a normalized stoichiometric ratio (NSR) in the range of 0.8 to 1.2 , while for sodium carbonate it was up to 2.4 , suggesting its much better sorption ability in comparison with sodium carbonate.

The work has been done in the framework of the research project of Minister of Science and Higher Education as a part of development project No NR05000910 „Modified sodium bicarbonate in the processes of dry purification of flue gases from various types of industrial installations". 


\section{LITERATURE CITED}

1. Kobus, D. (2011). Assessment of air pollution changes in Poland over 1997-2009 by using air quality index, Przemysł Chemiczny, 90/2, 200-207.

2. Regulation of the Minister of Environment from $22^{\text {nd }}$ of April 2011 on the installation emission standards [Rozporządzenie Ministra Środowiska z dnia 22 kwietnia 2011 r. w sprawie standardów emisyjnych z instalacji], Official Gazette No. 95, 5606, pos. 558.

3. Kilgallon, P.J., Simms, N.J. \& Oakey, J.E. (2007). Effectiveness of sodium bicarbonate for acid gas removal from waste incinerator flue gas. CWRM, annex CIWM, 8, part 2.

4. Keener, T.C. \& Davis, W.T. (1984). Study of the reaction of $\mathrm{SO}_{2}$ with $\mathrm{NaHCO}_{3}$ and $\mathrm{Na}_{2} \mathrm{CO}_{3}$. J.A.P.C.A, 34, 651-654.

5. Erdos, E., Mocek, K., Lippert, E., Uchytilova, V., Neuzil, L. \& Bejcek, V. (1989). Application of the Active Soda Process for Removing Sulphur Dioxide from Flue Gases, JAPCA, 39, 1206-1209.

6. Keener, T.C. \& Khang, S. (1993). Kinetics of the sodium bicarbonate - sulfur dioxide reaction. Chem. Eng. Sci. Vol. 48 No. 16, 2859-2865.

7. Garding, M. \& Svedberg, G. (1988). Modeling of dry injection flue gas desulfurization. JAPCA, 38 (10), 1275-1280.

8. Kimura, S. \& Smith, J.M. (1987). Kinetics of the sodium carbonate - sulfur dioxide reaction. AIChE Journal 33 (9), $1522-1532$.

9. US4588569. (1986). Dry injection flue gas desulfurization process using absorptive soda ash sorbent.

10. Warych, J. (1998). Purification of gases - the processes and apparatus [Oczyszczanie gazów - procesy i aparatura], WNT, Warsaw.

11. Szarawara, J. \& Jastrząb, K. (2005). The Polish process of purification of combustion gases on carbon sorbents, Przem. Chem. 84/6, 446-449.

12. Franc, M. \& Thijssen, M. (2011). U.S. Patent No. 7909272, Milling process.

13. Nowak, W., Szymanek, P. \& Sławiński, K. (2011). Drying of brown coal using electromagnetic mill, conference materials [Suszenie węgla brunatnego przy użyciu młyna elektromagnetycznego], conference materials, Conference within the competition "Funds for Science" [Fundusze dla Nauki] 28.11.2011, Warszawa.

14. ISO/DIN13320-1 Particle size analysis. Laser scattering methods, Part 1, General principles.

15. International Union Of Pure And Applied Chemistry, Physical Chemistry Division Commission On Colloid And Surface Chemistry Subcommittee on Characterization of Porous Solids (1994). Recommendations For The Characterization Of Porous Solids (Technical Report), Pure \& Appl. Chern., Vol. 66, No. 8, pp. 1739-1758.

16. Guidelines Alsthrom Propywer-Reactivity index. Alsthrom Propywer (1995). 